\section{Expansive Learning and Change Laboratory Model in Architectural Education: A Mexican Approach}

Anne K. Kurjenoja

Universidad de las Américas Puebla

Melissa Schumacher

Universidad de las Américas Puebla

Edwin Gozález-Meza

Universidad de las Américas Puebla

\section{Eduardo Gutiérrez-Juárez}

Universidad de las Américas Puebla
Latin American architecture and with it, architectural education frequently celebrates the insertion of local projects in the international design stardom as vanguard symbols of development, quality of life and local capacity for innovation. The material environment follows the logics in which the urban image and architectural objects are non-textual elements in a political, economic and social discourse. Thus, the 21th century architectural and urban re-invention is easily focused on the transformation of the material world to images of glamorous architectural objects and urban landscapes, de-territorialized from their local contexts, their people and the local narratives of place. How could Mexican architectural education respond to local, spatial, socio-cultural, territorial, environmental, economic and political demands to favorable impact the construction of material environment struggling under the clash between globalization, its neo-liberal architectural language, and the local emerging needs? Could it develop different and challenging focus areas, to seek new approaches to local problematics? How should critical architectural education trigger locally-based development innovation with potential to face global challenges of the professional world? In this context, Universidad de las Americas Puebla's (UDLAP) researchers' initial question was, how should critical architectural education trigger locally based development innovation with potential to face global challenges of the professional world?

The exploration of a new and locally viable architectural approach to sensible Mexican urban territories was triggered by a project seeking strategies to respond the collision between the traditional community of Cholula, Puebla, and the recent urban development around it informed by global economy and its architectural aesthetics. In a design workshop, socially responsible professional practices and sustainable environmental transformations were promoted in a context in which global forces are influencing local urban planning policies. Thus, this paper exposes Expansive Learning ${ }^{1}$ educational approaches experimented to trigger strategies for collaborative community development. These strategies were based on Social Urbanism, socially responsible New Localism2 and Regenerative Development Design $^{3}$ through bottom-up collaborative design and co-configuration work in which the architect adopts the role of a social and environmental mediator within the framework of Critical Realism (CR $)^{4}$.

\section{THE MEXICAN CHALLENGE: URBAN INCLUSION AND EXCLUSION}

Urban realities are products of different and changing urban associations or assemblages caused by encounters and clashes between economy, culture, urban development, public policy and social antagonisms5. In Mexico these as triggering forces of urban assemblages manifest themselves in the commodification of patrimony, creation of new public spaces and transformations of urban scale and image but also socio-economical fractures of urban territories ${ }^{6}$.

The notable characteristic of the contemporary urban processes is their growing relation to life styles converted to commodities making of cities more and more merchandise in the consumer culture. In 
developing countries as Mexico not all the population though is able to enjoy of urban life styles and their environments. The majority suffers of the unbalanced distribution of resources observable in the severely fractured urban territories with their exclusive, higher middle-class gated communities side by side with slums and urban belts of poverty, and massive lower-class living complexes and peri-rural areas tightly surrounding the ever-growing metropolitan areas. Thus, we can easily observe that the impact of the globalized economy and the urban development following it impact ways of appropriation, signification, habitation and domination of urban territories visible in the urban inclusion and exclusion?. These contexts of polarized cities are contexts of experiential life for some and absolute survival for the others.

The neo-liberal trend on Mexican public policies during the last 30 years settled urban planning and social-housing responsibility to private developers instead of local governments8. Therefore, the public-private alliances have converted to powerful management agents of urban territories, focusing their interest on the economically promising urban areas through spectacular, high cost urban developments. These urban tendencies, that have taken advantage of the lands of those poorly empowered habitants of the peri-rural territories, historical centers and traditional rural communities, trigger great social transformations in areas they impact through expropriations, expulsion of local population and insertion of intensive real-estate business. Thus, planners, real-estate agents and tourist industry have defined the course of the urban development, triggering processes of gentrification9. The result is the invisibility of the original local habitant whose everyday practices have been making and re-making the city until now. Urban public policy thus pretends to follow top-down strategies justified by sustainability, technology and culture as easily acceptable, beneficial and not questioned values promoting fantasies of wellbeing, resilience and economic development10 .

\section{TOWARDS NEW MODELS IN ARCHITECTURAL EDUCATION: THEORY FRAMEWORK}

The prevailing stance in the architectural tradition during the last 100 years referring knowledge production has been deeply rooted in the rationalist tradition of the valid knowledge based on measurable evidences and on rigorous and scientific understanding of the world ${ }^{11}$. It has been considered that this real, Cartesian knowledge should not be polluted by subjective values, the fact that has led us to search for value-free knowledge with emphasis on efficiency and technology ignoring the human condition and narratives and meanings attached to it. In the framework of Critical Realism, a transdisciplinary understanding of social, economic and environmental context is required to achieve a real, locally sensible and conceptually wide sustainability. This leads us to reconsider the approaches to learning, teaching and assessment in architecture to enhance learning skills in the framework of creative and critical thinking, collaboration and cooperation, conflict management, decision-making, problem-solving and planning beyond the narrow canonical, theoretical, professional or political limits ${ }^{12}$.

In these terms we should understand that the society and the social reality is produced and reproduced by its members and by the social relations and structures between them as products and conditions for the human activity. Thus, something fundamental to reinforce in architecture as professional practice, but also in architectural education, is the critical study of social structures in which architects work and architectural and urban products are inserted in ${ }^{13}$. "Critical realism regards nature as socially constructed or produced in two senses: it is materially shaped by social practices and it is existentially produced by cultural meanings, discourses and representations" ${ }^{14}$.

To complement this vision, other theories like Critical Urban Theory reinforces Critical Realism through adopting concepts such as critique of ideology, in Brenner's words "critique of power, inequality, injustice, and exploitation, at once within and among cities"15. These, as he points out, are grounded on the right to the city, described by him as the pursuit for a "more democratic, socially just, and sustainable form of urbanization" 16 to reach a balance between what is technically possible and what is culturally appropriate and morally, congruent, and politically right ${ }^{17}$.

The insertion of cultural artifacts, such as architectural objects or public spaces conceptualized through human life and its practices is a cutting-edge action for the environmental analysis to overcome the split between the Cartesian individual and the societal structure of a community. As Engeström points out, "The individual could no longer be understood without his or her cultural means; and society could no longer be understood without the agency of individuals who use and produce artifacts" ${ }^{\prime 18}$. Thus, material culture, all kind of objects and artifacts along with the constructed environment is not just raw material for the formation of logical operations and objects but cultural entities; object orientedness of action should become the key issue for the understanding of the human being ${ }^{19}$.

In the framework of Cultural-Historical Activity Theory (CHAT) conceptual tools such as dialogue, multiple perspectives and networks of interacting activity systems can be understood. A collective artifact-mediated and object-oriented activity system observed through its network relations with other activity systems can be distinguished and analyzed as a socio-cultural and environmental discourse. The material culture reflects the multivoicedness of activity systems of the human society ${ }^{20}$. He observes the following: "An activity system is always a community of multiple points of view, traditions and interests [...] the multivoicedness is multiplied in networks of interacting activity systems. It is a source of trouble and a source of innovation, demanding actions of translation and negotiation"21. Activity systems have their own historicity and thus Engeström suggests that history itself should be studied as that of local history of performativites and their material outcomes (in this case architectural creation and its products ${ }^{22}$. Thus, an expansive contextual transformation is in process when the goals of design practices are re-conceptualized through dialogue and collaboration to embrace a radically wider horizon of possibilities ${ }^{23}$. In the context of architectural education, the collective endeavor of learners, community and professionals could be engaged producing culturally new patterns of design practices 
through collaboration24. Thus, learners themselves are involved in constructing and implementing a radically new, wider and more complex goals and concepts for their own design practices 25 in the framework of bottom-up reflexive strategies of creation.

Human beings are immersed in the world of social semiotic meanings expressed through different means of transmission of signifying codes and thus, this environment of meanings forms the framework for socio-cultural narratives ${ }^{26}$. The Systemic Functional Semiotics (SFS) approach makes it possible to specify the different distinctive semiotic processes and practices in the development of constructed environments be they imprinted by local or global discourses. Halliday (1985) highlights that any semiotic text will represent some aspect of the human experience of the world, or of some experiential or ideational function and thus the material culture is a narrative of human existence. These meanings imprinted in the material environment manifest certain socio-cultural reality. That is, the material environment consists of a particular lexico-grammatical system of its own that offers alternatives for the expression of different contextual and socio-cultural messages; every choice of the expressive elements and signs made is related to the social functioning of the utterance ${ }^{27}$. The Change Laboratory, as defined by Engeström ${ }^{28}$, is a microcosm in which potential new ways of working can be experienced and experimented. The idea of Change Laboratories is based on the concept of a knowledge community of learners, teachers, professionals and local stakeholders and community emerging of an environment in which the knowledge and rationality are not clearly separated from emotion, figurative speech and action. The main goal is to trigger innovation processes through which something new and different emerges. Questions and questioning are crucial in making the laboratory model functional, as questioning shakes conventional models triggering cycles of innovation; "questions and problems of understanding are the moving force for progressive knowledge building" 29 . In these processes of shared problem solving, agents with different information and knowledge improve collectively their understanding of the problematics through social interaction. Thus new ideas and innovations emerge between people and the solution creation is not only a matter of creative professionals such as architects, but requires a fundamental reorganization of the practices of the whole community involved. This knowledge creation work cannot be accomplished by epistemological means only but participating in grass root cultural practices and by becoming member of real and innovative knowledge communities of professionals and users to promote creative use of knowledge and solutions produced ${ }^{30}$.

\section{CHANGE LABORATORY IN ARCHITECTURAL EDUCATION: A MEXICAN MODEL}

The framework of Engeström's Change Laboratory allows the implementation of a methodology promoting a design of an objective and socially responsible architecture with potential to detonate beneficial transformations in urban and rural communities. These processes may be introduced as a device for social transformation as a structured activity system in which collaborative participation of different actors can be periodically modified as a result of the assessment of collaborative design work and its outcomes.

The model proposed by us allows to understand each one of the actors and their motives for participating to an activity system by means of expansive learning as an encounter between different ideas and conditions in which contradictions and accumulating tensions are negotiated in order to create a bottom-up functional and socially inclusive architectural or urban outcome satisfying local needs. Actors to participate in the process of obtaining a final architectural or urban learning outcome are students, professors, professionals, technicians, users, social actors and other stakeholders, who are involved in a process of defining private, public and social needs in the context of an interconnected cyclical process of co-configuration work ${ }^{31}$. Through this, architecture students acquire professional knowledge and ethic stance responding to the manifested needs defined by users, social actors and other stakeholders considering their different stances regarding problematics to resolve.

In the generation of knowledge for the design process, the understanding of various criteria is necessary. These criteria are usually explicit in norms, laws and regulations that a society applies to control the diversity of ideational manifestations but also as parameters and measures indispensable to have a better control of the environmental development. The successful insertion of a design product in a community environment is achieved through understanding the latter as a complex object with a specific use created through negotiation of conflicts, dilemmas and disturbances. The debate, the confrontation and the mediation between participating actors supported by the experience of the technicians and professionals, will be considered as a functional system triggering significant evolution of learning processes. Once ideas and concepts for the solution of an architectural or urban problem are achieved, the modeling process may begin with the simulation of a product, a prototype, that should meet the established criteria through co-configuration. In case the modeling does not meet the expectations of the functional system process, negotiations and debates should be re-started to reach the acceptance of a final model by all the participating collaborators.

With a model as a basis, the development of a final project may begin considering the conservation of different narratives that allow the preservation of the local identity, meanings and urban image without insensible transformations. This process of expansive learning in architecture through Change Laboratory model also allows the consolidation and improvement of methodologies for future functional cycles in similar kind of problem solving situations and conditions. Learning and social innovation will thus emerge through shared labor including reflection and improvement of ideas triggering a sensible transformation of material, habitable environments improving the quality of life. 


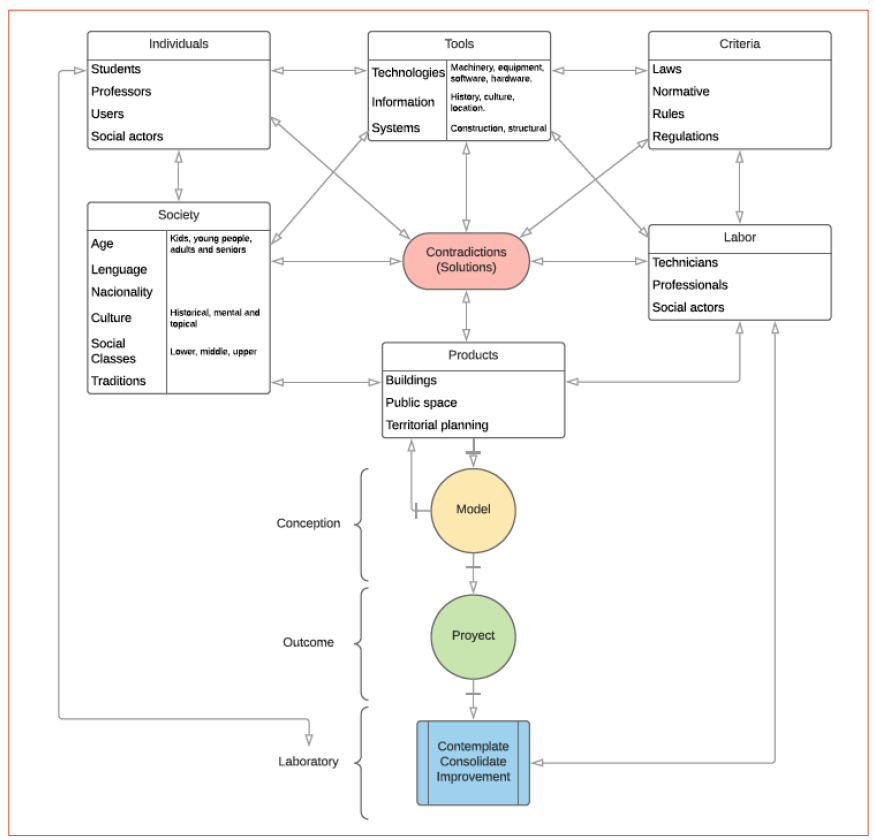

Figure 1. Change Laboratory model in Architectural Education. Author: Edwin González Meza (2018).

\section{REGENERATIVE-SOCIAL-DESIGN IN PRACTICE: CHOLULA, PUEBLA}

Involving a group of learners with local communities, professionals and technicians is part of a critical process leading architecture students to discover, analyze, and assume complexity between social-spatial reality and project needs with a New Localism focus ${ }^{32}$. This practice pursuits the inclusion of local communities in a critical framework of global economy. Katz and Nowak point out that local inclusion is multidimensional rather than a simple problem-solving process requiring "new norms of growth, governance, and finance" ${ }_{33}$. In addition, this practice on the local should be aligned with a critical view for an

"evaluating attitude towards reality, a questioning rather than acceptance of the world as it is...it leads to a position not only necessarily critical in the sense of negative criticism, but also critically exposing the positive and the possibilities of change, implying positions on what is wrong and needing change, but also on what is desirable and needs to be built on and fostered" ${ }^{\prime 3}$.

New Localism and its critical perspective correspond to different social design practices that were conducted in student projects in Cholula informed by Regenerative Design and Social Urbanism, two methods that fit Mexico's complex reality. Regenerative Design emerges from the idea of the human being as the source of wealth, health and regeneration, and the place as the interphase-scale that combines land uses, community development and environmental construction ${ }^{35}$. Adding the role of designer as the key agent of change, regenerative design shares the idea that living systems have the capacity to co-evolve to new levels of diversity, complexity, creativity, and life. Mang \& Haggard established different regenerative principles, where becoming partners of the place leads to a strategic alliance among stakeholders36.

The context of our experimental regenerative-social-design workshop, Cholula, the Sacred City, with a millenary socio-spatial structure is facing the emergence of gentrification threatening its identity and cultural landscape due to New Urbanism triggering processes of socio-economic, identity and material changes colliding with ancestral settlement patterns. Research work was done by direct observation and experiential-qualitative analysis of landscape transformations detonated by public policies of the state and municipality governments and by market forces promoting gentrification and demographic dynamics shaping urban development. A special attention was paid to the conflict between community resistance and urban-economic trends and changes analyzed not only as population displacements but also through changes in land uses, urban density, landscape and in socio-spatial dynamics. It was not only about changes in the image of the city in a broad sense, but also about endangering the existing functional neighborhood or barrio organization.

In Cholula solutions to the conflict between the rapidly growing land speculation and the local system of traditional communal lands and their uses were suggested to give alternatives to "the paradigms on peri-urbanization where the market forces guide urban growth, development plans are short-term political visions and exclusive land policies segregate and disperse the social fabric" ${ }^{37}$. In the framework

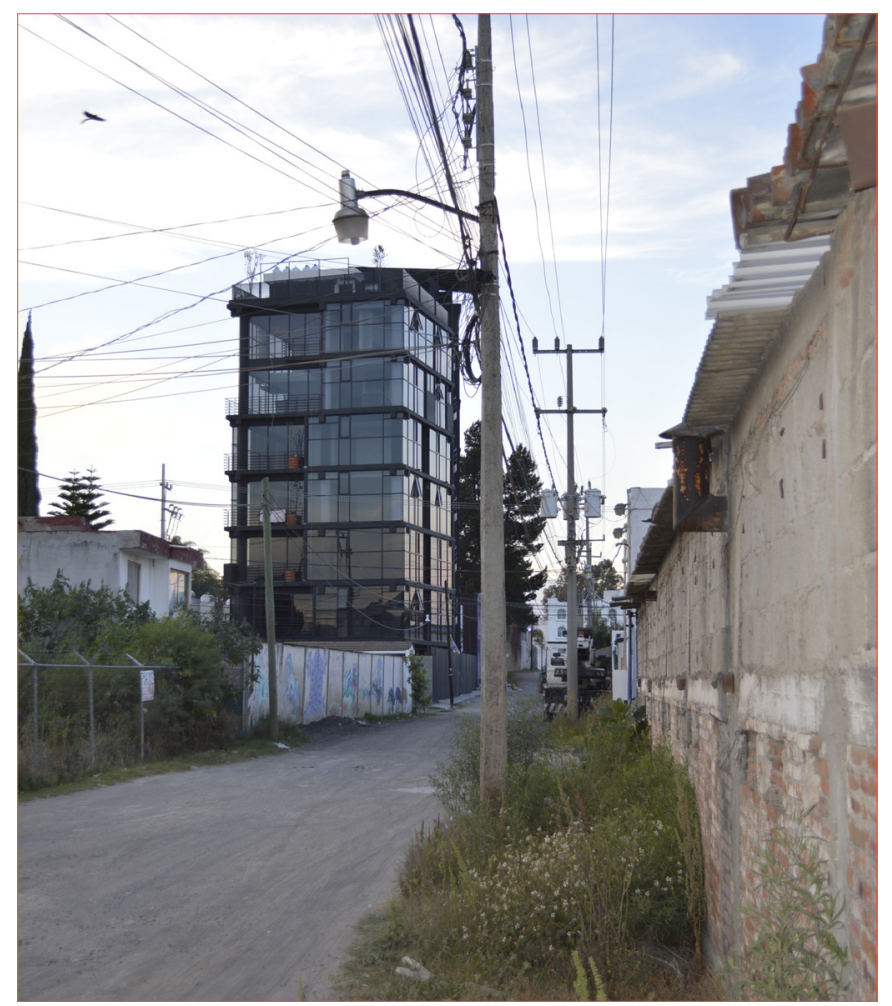

Figure 2. Clash between traditional urban structure and new urban developments. Photos: Eduardo Gutiérrez Juárez (2019). 
of this project, in 2017 a co-configuration workshop was organized in cooperation with the department of Land Management of the Technische Universität München, Germany, and the local community in order to create an urban milpa system, being the milpas an ancestral agricultural and still existing auto-production mechanism. The interaction between students, specialists and local community made possible the creation of rural-urban projects that not only complemented the modern development needs, but also took the students down to the simplest life needs of the local population. It sensitized them of the importance of the protection of the intangible heritage and the signifying elements that shape the territory ${ }^{38}$. This workshop was informed also by the strategic territorial analysis ${ }^{39}$ and the socio-spatial management model40 related to regenerative-social design processes.

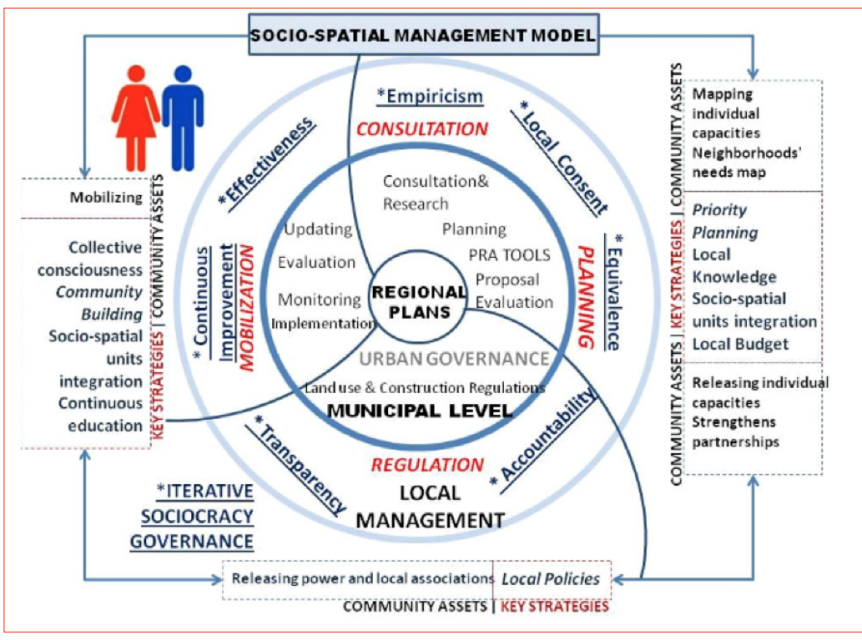

Figure 3. Socio-spatial management model loops.41 (Author: Melissa Schumacher 2017)

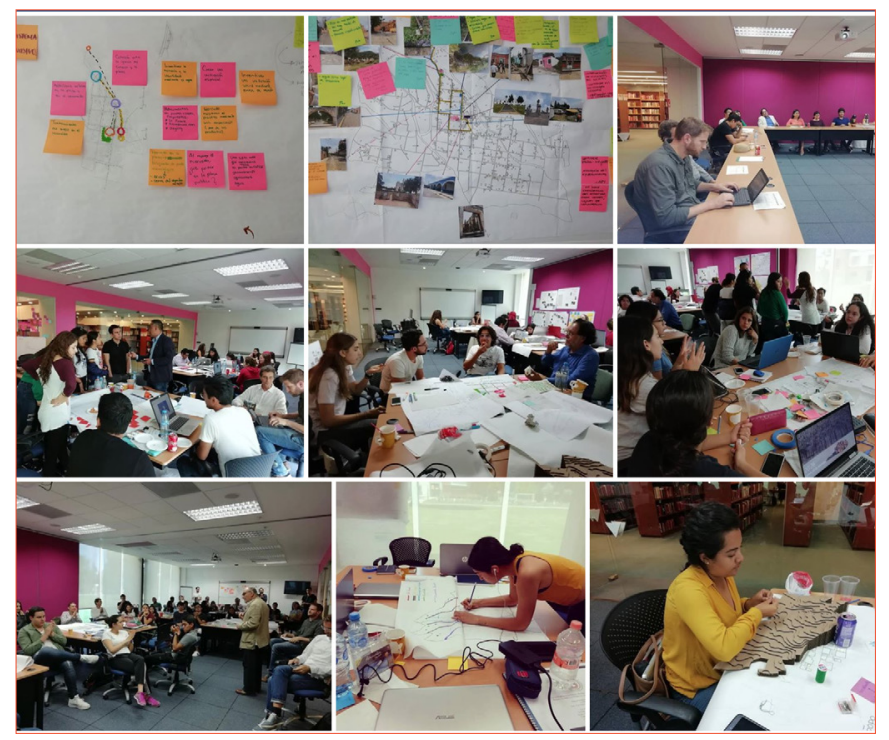

Figure 4. Co-configu ation activities of the Cholula-project (Photos: Melissa Schumacher 2018)

\section{CONCLUSION}

In Mexican urban peripheries, traditional urban districts and rural areas, spaces are subject to diverse processes of transformation, anarchy and changes produced by complex networks of local cultural and social performativities beyond the conventional architectural and urban theory. Our work proposes to reconsider the use of semiotic and phenomenological understanding of these territories to comprehend all those undefined human experiences of occupying space revealing sensible relations between the human being and the place and means of production of urban meaning through a cultural, social and historical individual and collective body ${ }^{42}$. With our model we propose to extend the sense of expansive learning through a locally structured Change Laboratory model with the collaboration between learners, teachers, professionals and local communities to explore alternative approaches to architectural teaching and learning as well as professional practices sensible to Mexican realities facing external political and economic demands. We perceive an urgent need to go beyond the modern geographical, spatial and technological descriptions of the conditions of human habitable environments as they are not quite able to explain the character and the grass root demands of the Mexican conditions. As García Canclini points out, Mexican urban territories are characterized by concentrations of heterogeneous communities and their urban cultures transformed by historical, cultural and social processes. He describes these realities as those of a diversity of micropolis conditioned by the accumulation of historical cultural meanings mingled with contemporary cultural influences reconstructing identities and refreshing urban memories and the sense of place that makes them habitable ${ }^{43}$. The use of our model permits to locate subjects and their sociability at the base of the urban and architectural conceptualization triggering constructivedestructive cycles of collaborative creation in which borders between the community, learners and experts will disappear. To respond to local challenges will lead us "to a holistic approach to the territory as a complex-multidimensional space [...] with the capacity to build unity in diversity" 44 .

\section{Notes}

1. Yrjö Engeström, Learning by Expanding (Helsinki: Orientakonsultit, 1987), "Expansive Learning at Work: Toward an Activity Theoretical Reconceptualization," Journal of Education and Work 14, no.1 (2001): 133-156, https://doi. org/10.1080/13639080020028747.2001, "Enriching the Theory of Expansive Learning: Lessons from Journeys Toward Coconfiguration," Mind, culture, and activity 14, no.1-2 (2007): 23-39, https://doi.org/10.1080/1074903070130 7689.2007 and "Expansive Learning: Towards an Activitytheoretical Reconceptualization," in Contemporary theories of learning. Learning Theorists ... In Their Own Words, ed. Knud Illeris (London and New York: Routledge, 2009), 53-74.

2. Bruce Katz and Jeremy Nowak, The New Localism: How Cities Can Thrive in the Age of Populism (Washington D.C.: Brookings Institution Press, 2018). 
3. Pamela Mang and Ben Haggard, B., Regenerative Development: A Framework for Evolving Sustainability, (Hoboken, NJ: Wiley Online Library, 2016).

4. Yona Sipos, Bryce Battisti and Kurt Grimm, "Achieving Transformative Sustainability Learning: Engaging Head, Hands and Heart," International Journal of Sustainability in Higher Education 9 no.1 (2008): 68-86, https://doi. org/10.1108/14676370810842193.

5. Ignacio Farías, I., "Introduction: Decentring the Object of Urban Studies," in Urban Assemblages: How Actor-network Theory Changes Urban Studies, ed. Ignacio Farías and Thomas Bender, (London: Routledge, 2010), 1-24.

6. Ernst F. Schumacher, Small is Beautiful: A Study of Economics as if People Mattered, (New York: Harper Perennial, Reprint, 2010), 12.

7. Kurjenoja, Ismael and Hernández, "Introducción. Procesos urbanos en Tiempos Neoliberales" in Ciudad, Capital y Cultura, coord. Anne K. Kurjenoja, María E. Ismael and Adrián Hernández, (Mexico City: Itaca, 2018), 9.

8. Melissa Schumacher, "Peri-urban Development in Cholula, Mexico," Technische Universität Munchen. http://mediatum. ub.tum.de/?id=1276269, 38 .

9. Kurjenoja, Ismael and Hernández, "Introducción," 12.

10. Anne K. Kurjenoja and María E. Ismael, "Puebla, ¿Ciudad Creativa, Innovadora e Inteligente?" in Ciudad, Capital y Cultura, coord. Anne K. Kurjenoja, María E. Ismael and Adrián Hernández, (Mexico: Itaca, 2018), 33.

11. Kevin Lambkin's "The Hegemony of Rationalism and It's Influence on Organizations," ALAR: Action Learning and Action Research Journal 3 no.1 (1998), 3., cited in Sipos, Battisti and Grimm, "Achieving Transformative Sustainability Learning," 70.

12. Sipos, Battisti and Grimm, "Achieving Transformative Sustainability Learning," 68-86.

13. John Huckle, "Critical Realism-A Philosophical Framework for Higher Education for Sustainability," in Higher Education and the Challenge of Sustainability, eds. Peter B. Corcoran and Arjen E.I. Wals, 33-46, (Denmark: Kluwer, 2004), https://doi. org/10.1007/0-306-48515-X_4, 38.

14. Idem.

15. Neil Brenner, "What is Critical Urban Theory?"

City 13, no. 2-3 (2009), 198-207, https://doi. org/10.1080/13604810902996466, 198.

16. Idem.

17. Huckle, "Critical Realism," 42

18. Engeström, "Expansive Learning," 53-74.

19. Engeström, "Expansive Learning," 54.

20. Engeström, "Learning by Expanding," 33.

21. Engeström, "Learning by Expanding," 174

22. Engeström, "Expansive Learning at Work," 136, 137
23. Engeström, "Learning by Expanding," 174.

24. Engeström, "Expansive Learning at Work," 139.

25. Engeström, "Expansive Learning: Towards an Activitytheoretical Reconceptualization," 2.

26. Michael O'Toole, M., "A Systemic-functional Semiotics of Art," Semiotica 82 no. 3-4 (1990), 185-210, https://doi. org/10.1515/semi.1990.82.3-4.185, 186.

27. O'Toole, "A Systemic-functional Semiotics," 187.

28. Engeström, "Learning by Expanding," 277-278.

29. Carl Bereiter's and Marlene Scardamalia's Surpassing Ourselves: An Inquiry into the Nature and Implications of Expertise (1993), cited in Sami Paavola, Lasse Lipponen and Kai Hakkarainen, "Models of Innovative Knowledge Communities and Three Metaphors of Learning," Review of Educational Research 74 no.4 (2004), 557-576, https:// www.researchgate.net/publication/220042022_Models_ of_Innovative_Knowledge_Communities_and_Three_ Metaphors_of_Learning, 564.

30. Paavola, Lipponen, and Hakkarainen, "Models of Innovative Knowledge Communities," 570.

31. Engeström, "Enriching the Theory of Expansive Learning," 23-36.

32. Katz and Nowak, The New Localism.

33. Katz and Nowak, The New Localism, 17.

34. Peter Marcuse, "Whose Right (s) to What City?" in eds. Neil Brenner, Peter Marcuse and Margit Mayer, Cities for People, not for Profit, (London: Routledge, 2012), 24.

35. Mang and Haggard, Regenerative Development, Chapter 3.0.

36. Mang and Haggard, Regenerative Development, VI.

37. Melissa Schumacher, "Peri-urban development," 170.

38. Pamela Durán Díaz, "El Río como Eje de Vertebración Territorial y Urbana: El Río San Marcos en Ciudad Victoria, México," Universitat Politècnica de Catalunya, (2014), Chap. 1.

39. Durán Díaz, "El Río como Eje de Vertebración Territorial", Chap 3.1.

40. Melissa Schumacher, "Peri-urban Development," 154.

41. Idem.

42. Anne K. Kurjenoja and María E. Ismael, "Informal Mexican Urbanity and Subaltern Knowledge: The Case of Xonaca, Puebla," The International Journal of Critical Cultural Studies 15 no.3 (2017), 1-19, https://doi.org/10.18848/2327-0055/ CGP/v15i03/1-19, 1.

43. Néstor García Canclini, Imaginarios urbanos, (Buenos Aires: Editorial Universitaria de Buenos Aires, 1997), 109-111.

44. Melissa Schumacher, "Peri-urban Development," 170. 